\title{
Ethylenediamine in alkaline cooking of jute stick for producing dissolving pulp
}

\author{
M. Sarwar Jahan ${ }^{1 *}$, Halima Rahman ${ }^{1}$, Purabi Rani Samaddar ${ }^{2}$ and Mostafizur Rahman ${ }^{2}$ \\ ${ }^{1}$ Pulp and Paper Research Division, BCSIR Laboratories, Dhaka, Dr. Qudra-I-Khuda Road, Dhaka-1205, Bangladesh. \\ ${ }^{2}$ Department of Chemistry, Eden Girls College, Dhaka.
}

\begin{abstract}
Jute stick is the woody portion of jute plant. It remains as the leftover after extracting the fibre. The ratio of the stick to fibre is about 2.5:1. For producing dissolving pulp, prehydrolysis is carried out prior to pulping to remove hemicelluloses from the lignocelluloses. In this investigation ethylenediamine (EDA) was used with the cooking liquor to remove hemicelluloses from the jute stick. Increasing EDA charge in soda and kraft liquor decreased pentosans content in the pulp. EDA in kraft liquor showed lower kappa number and pentosans content than in the soda-liquor. Prehydrolysis further improved cellulose content and kappa number of jute stick pulp with the sacrifice of pulp yield. The bleachability of soda-EDA pulp was inferoior to the kraft-EDA and prehydrolysed soda-EDA in ECF bleaching sequences. The final brightness of soda-EDA pulp was $85.1 \%$ and kraft-EDA pulp $89.7 \%$. Degraded cellulose $\left(\mathrm{R}_{18}-\mathrm{R}_{10}\right)$ in soda-EDA and kraft-EDA pulps was lower than prehydrolysed pulps. Dissolving pulp can be produced to $93 \%$ purity without prehydrolysis by reinforcing EDA in kraft liquor.
\end{abstract}

Keywords: Jute stick; Dissolving pulp; Ethylenediamine; Delignification; Pentosan dissolution

\section{Introduction}

Jute has played a significant role in the socio-economic development of Bangladesh. Once it was regarded as the golden fiber of Bangladesh as it created employment opportunity and generated foreign currency. To regain the lost glory of jute, its diversified uses are needed. Jute stick is the woody portion of jute plants. It remains as the leftover after extracting the fibre (Pandey et al., 1995). The ratio of the stick to fibre is about 2.5:1. Conventionally, jute stick is used as fuel wood, fencing material in the rural area. Jute stick contains considerable amount of cellulose with lignin and hemicelluloses. Therefore, it is a potential raw material for pulping.

Due to the scarcity of lignocellulosic materials for pulp production in Bangladesh, interests are growing on alternative lignocelluloses. Jute stick is one of the most important alternative lignocelluloses in Bangladesh, which falls under the category of hardwood. The annual production of jute stick in the country is around 3.0 million tonnes (IJSG 2014, http://jute.org/statistics_search.php). Several studies have been carried out on the pulping of jute stick. Das (1980) studied on the feasibility of jute stick pulping. The author considered it economically viable for Indian paper pulp plant. Das et al., (1987) also prepared a variety of boards from jute stick suitable for use in making of furniture, table tops, partitioning materials, false ceilings, etc. Day et al., (2007) used jute stick for producing high purity cellulose pulp by pre-hydrolysis followed by kraft process. The yield of cellulose was 93\%. Subsequently, CMC and MCC were made from this pulp. In our previous study (Matin et al., 2015), biorefinery concept was initiated in producing dissolving pulp from jute stick by pre-hydrolysis kraft process. Final pulp was produced with $92 \% \alpha$-cellulose and $89 \%$ brightness after $D_{0} E_{p} D_{1} E p D_{1}$ bleaching. The produced dissolving pulp can be used in rayon production.

Dissolving pulp is produced from wood using the prehydrolysis kraft or acid sulfite processes (Biermann 1993, Hinck, et al., 1985). This pulp is a chemically refined bleached pulp composed of more than 90 percent $\alpha$-cellulose, which can be used in producing cellophane and rayon, cellulose esters, cellulose ethers and cellulose derivatives (Sjöström, 1981). Dissolving pulp should have special properties, such as a high level of purity, uniform molecular-weight distribution and the reactivity and accessibility of the cellulose to chemicals (Krässig 1993). Reactivity of dissolving pulp could be improved by cellulase treatment (Miao et al., 2014). Grinding and PFI refining increased accessible surfaces in the compact cellulose structure via fiber cutting and fibrillation, consequently increased Fock reactivity of a dissolving pulp (Tian et al., 2014).

\footnotetext{
*Corresponding author: E-mail: sarwar2065@yaho.co.uk
} 
An extra capital investment is needed for prehydrolysis. Therefore, we have tried to omit the prehydrolysis step by introducing cooking additive, which will dissolve hemicellulose to a considerable amount in the cooking stage. It has been reported in our earlier study (Jahan and Farouqui 2000; Jahan and Farouqui 2001) that ethylenediamine (EDA) in soda liquor increased delignification and hemicellulose dissolution of jute. MacLeod et al. (1984) also observed that the soda-EDA process dissolved a large amount of xylan in pulping of spruce. In our earlier studies, it was observed that EDA in soda liquor increased delignification and pentosans dissolution without affecting cellulose (Jahan et al. 2008, Jahan 2009).

The objective of this study was to evaluate EDA in soda and kraft liquor for producing dissolving pulp from jute stick. The effect of EDA in soda and kraft liquor of prehydrolysed jute stick was also studied. With and without prehydrolysed sodaand kraft-EDA pulps were bleached and final pulp properties were evaluated.

\section{Materials and methods}

\section{Raw materials}

Jute stick was collected from the local market in Dhaka. It was sun-dried and cut to $2-3 \mathrm{~cm}$ in length. The moisture content of raw materials was determined according to TAPPI Standard Methods (T 18m-53). After determination of the moisture content of air dried raw materials equivalent to 250 gm o.d. (oven dried) was weighed separately in a polyethylene bag for subsequent cooking experiments. Jute stick contained about 39\% $\alpha$-cellulose, 18\% hemicelluloses and $25 \%$ lignin with other minor ingredients (Matin et al., 2015).

\section{Prehydrolysis}

The prehydrolysis was carried out in an electrically heated stainless steel digester of 51 capacity, rotating at $1 \mathrm{rpm}$. Water prehydrolysis was carried out at $170{ }^{\circ} \mathrm{C}$ for $1 \mathrm{~h}$. The jute stick to liquor ratio was 1: 5 . The time required to raise max temperature was $60 \mathrm{~min}$. The liquor was drained after prehydrolysis.

\section{Prehydrolysis liquor analysis}

The total solid content in the prehydrolysis liquor (PHL) was determined gravimetrically by drying $10 \mathrm{~mL}$ sample at $105^{\circ} \mathrm{C}$ to constant weight. The dissolved lignin in the PHL was measured based on the UV/Vis spectrometric method at wavelength $205 \mathrm{~nm}$ (TAPPI UM 250).
For sugar analysis, PHL was filtered to remove any solid particle with filter paper. A vial containing $1 \mathrm{~mL}$ of the PHL and $4 \mathrm{~mL} 4 \mathrm{~N}$ sulfuric acid was sealed and autoclaved at $121^{\circ} \mathrm{C}$ for $60 \mathrm{~min}$. Component sugars and organic acids were analyzed by high-performance liquid chromatography (HPLC) equipped with refractive index and UV detection (Shimadzu, Columbia, MD), using the Aminex HPX-87H column (Bio-Rad, Hercules, CA). The column was operated with a $5 \mathrm{mM}$ sulfuric acid mobile phase at a flow rate of 0.6 $\mathrm{mL} / \mathrm{min}$ and oven temperature of $60{ }^{\circ} \mathrm{C}$. Samples were filtered through $0.22 \mu \mathrm{m}$ syringe filters prior to injection. The sugar contents in oligomeric form in the pre-hydrolysis liquor were calculated from the difference of the monomeric sugar contents between pre and post hydrolysis PHL.

\section{Cooking}

Prehydrolysed and non-prehydrolysed jute stick were cooked in the same digester. The following parameters were kept constant in the soda process:

-Active alkali charge - varied from 16 - $24 \%$ (as $\mathrm{NaOH})$ on o.d jute stick

-Liquor to fiber ratio- 5:1

-Temperature $-170^{\circ} \mathrm{C}$.

-Cooking time - $120 \mathrm{~min}$.

- EDA charge $-0-40 \%$ on od raw materials

\section{Bleaching}

Pulps were bleached in $D_{0} E_{p} D_{1} E_{p} D_{2}$ bleaching sequences. The bleaching was done in polyethylene bag. The $\mathrm{pH}$ of bleach liquor was 2-2.5 in $\mathrm{D}_{0}$. The bleaching continued to 45 min at $70^{\circ} \mathrm{C}$. Alkaline extraction was carried out with $2 \%$ $\mathrm{NaOH}$ and $0.5 \% \mathrm{H}_{2} \mathrm{O}_{2}$ at $70{ }^{\circ} \mathrm{C}$ for $120 \mathrm{~min}$. The consistency was 10 in all stages. In the $\mathrm{D}_{0}, \mathrm{D}_{1}$ and $\mathrm{D}_{2}$ stages $\mathrm{ClO}_{2}$ charges were 2,1 and $0.5 \%$, respectively. The time of $\mathrm{D}_{1}$ and $\mathrm{D}_{2}$ stages were $120 \mathrm{~min}$ at $70^{\circ} \mathrm{C}$.

\section{Evaluation of pulps}

Pulp tests were performed according to the Standard Methods of the Technical Association of the Pulp and Paper Industry (TAPPI, Atlanta, GA): kappa number (T 236 cm-85); brightness (T 452 om-92); viscosity (T 230 om-89); carbohydrate (T249 cm00); $\alpha$-cellulose (T 203 om-88); and alkali solubility $\mathrm{S}_{10}$ and $\mathrm{S}_{18}$ (T $\left.235 \mathrm{~cm}-85\right)$. Alpha-cellulose is the pulp fraction resistant to a treatment in an aqueous solution containing $17.5 \%$ sodium hydroxide and indicates undegraded, high molecular weight cellulose content in pulp. Alkali solubilities $\mathrm{S}_{10}$ and $\mathrm{S}_{18}$ provide information on the low 
molecular weight carbohydrates (degraded cellulose and hemicellulose) in pulp. A $10 \%$ sodium hydroxide solution dissolves both degraded cellulose and hemicellulose $\left(\mathrm{S}_{10}\right)$ whereas hemicellulose is soluble in an $18 \%$ sodium hydroxide solution $\left(\mathrm{S}_{18}\right)$. All pulp properties were analyzed in duplicate.

\section{Results and discussion}

The variety of jute stick used in this investigation needed drastic cooking conditions to get a bleachable pulp. Table 1 shows the effect of alkali charge on the yield, residual lignin and pentosans. It is seen that jute was defibered chemically only at alkali charge of $24 \%$. At $16 \%$ alkali charge, yield of pulp was $76.5 \%$ with pentosan content $22.1 \%$, which dropped to $18.4 \%$ with the addition of $10 \%$ EDA in soda liquor. However the cooked material did not defibrate. With the increased of alkali charge to $18 \%$ in $10 \%$ EDA pentosan content further decreased to $17.1 \%$. With the increase of EDA addition the pentosans decreased, but jute stick did not defibrate. The minimum alkali charge is $24 \%$ at a cooking time $2 \mathrm{~h}$ and $170^{\circ} \mathrm{C}$.

Effect of EDA on delignification and pentosan dissolution from jute stick

Therefore, the effect of EDA charge in soda and kraft liquor on the delignification and pentosan dissolution from the jute stick was studied at the alkali charge of $24 \%$. The results are given in Table 2 . At $0 \%$ EDA charge, kappa number of soda pulp was 42.6 , while the kappa number of kraft pulp was 28.5. The kappa number decreased to 35.0 and 20.0 with the addition $40 \%$ EDA in soda and kraft liquor, respectively (Table 2). As shown in Table 2, the kappa number and pentosans declined with increasing EDA charge in soda or kraft liquor. Julien and Sun (1979) also observed better delignification when EDA was added in soda liquor. Jahan and Farouqui (2000) also showed improved delignification and higher pentosan dissolution in presence EDA in soda liquor. Presence of amine in soda liquor altered the molecular weights of the dissolved lignin fraction and delignification is also associated with negative reduction potential of pulping additive (Kubes and Bolker 1978). The addition of 10\% EDA in soda liquor decreased pentosan content from 21.6 to $19.2 \%$, while in kraft liquor it decreased from 16.1 to $14.6 \%$.

As shown in Fig. 1 and Table 2, kappa number of soda pulp did not reach to the target kappa number of 25 even with addition of $40 \%$ EDA charge. With the addition of $10 \%$ EDA charge in kraft process, kappa number reached to 23.6. The slightly decreasing trend in pulp yield with increasing EDA addition may be explained by dissolution of hemicelluloses and lignin (Jahan and Farouqui 2000). This result indicated that substantial increase in alpha-cellulose in pulp, which could be attributed to the selective removal of hemicelluloses and stabilization of alpha-cellulose as indicated by Kubes and Bolker (Kubes and Bolker 1978, Kubes et al 1978).

Table I. Effect of alkali charge on the pulping of jute stick

\begin{tabular}{cccc}
\hline $\begin{array}{c}\text { Alkali charge }(\% \\
\text { as } \mathrm{NaOH})\end{array}$ & Yield $(\%)$ & Lignin $(\%)$ & Pentosan s \\
\hline 16 & & $25)$ \\
\hline 18 & 76.5 & $22.8(15.4)$ & 22.1 \\
20 & 67.7 & $17.5(10.7)$ & 22.4 \\
22 & 60.9 & $12.1(6.0)$ & 21.9 \\
24 & 49.9 & $6.5(2.8)$ & 22.8 \\
$16(10 \%$ EDA $)$ & $43.8 *$ & $24.1(15.0)$ & 18.4 \\
$18(10 \%$ EDA $)$ & 62.3 & $21.6(13.2)$ & 17.1 \\
$18(20 \%$ EDA $)$ & 61.3 & $20.1(11.5)$ & 15.6 \\
$18(40 \%$ EDA $)$ & 57.1 & $18.2(9.0)$ & 13.2 \\
$20(10 \%$ EDA $)$ & 49.5 & $12.7(6.5)$ & 17.6 \\
\hline
\end{tabular}

*defibered 
Table II. Effect of ethylenediamine on the pulping of jute stick

\begin{tabular}{ccccccc}
\hline \multicolumn{3}{c}{ Soda process } & \multicolumn{3}{c}{ Kraft process } \\
\hline $\begin{array}{c}\text { EDA } \\
(\%)\end{array}$ & $\begin{array}{c}\text { Pulp yield } \\
(\%)\end{array}$ & $\begin{array}{c}\text { Kappa } \\
\text { Number }\end{array}$ & Pentosans (\%) & $\begin{array}{c}\text { Pulp yield } \\
(\%)\end{array}$ & Kappa Number & Pentosans (\%) \\
\hline 0 & 43.8 & 42.6 & 21.6 & 37.8 & 28.5 & 16.1 \\
10 & 39.2 & 40.6 & 17.2 & 35.7 & 23.6 & 13.6 \\
20 & 39.3 & 39.1 & 15.7 & 35.5 & 22.3 & 13.1 \\
30 & 38.9 & 37.2 & 15.0 & 35.5 & 21.2 & 12.7 \\
40 & 38.8 & 35.0 & 14.1 & 35.3 & 20.0 & 11.4 \\
\hline
\end{tabular}

Prehydrolysis and effect of EDA on delignification and pentosan dissolution in pulping

It is seen from the earlier section that hemicelluloses did not sufficiently dissolve in pulping of jute stick by soda-EDA or kraft-EDA processes. Therefore, jute stick was pre-hydrolysed at $170^{\circ} \mathrm{C}$ for $1 \mathrm{~h}$. Table 3 shows that the prehydrolysed yield was $89.8 \%$, which was much higher than the earlier study (Matin et al. 2015). It indicates that jute stick used in this study was completely different in nature. Dissolved biomass consisted of $5.23 \%$ sugars, $0.52 \%$ lignin and $0.85 \%$ acetic acid. Commercial exploitation of these by-products will provide additional revenue for the pulp mill.
Furfural can be one of the possible products from the dissolved hemicelluloses in the PHL (Liu et al. 2013). The dissolved hemicelluloses can also be used in producing ethanol, lactic acid, propionic acid, succinic acid by saccharification followed by fermentation (Bustos et al., 2007, Hughes 2008). Acetic acid in the prehydrolysis liquor can be separated and concentrated by reactive extraction with tri-n-octylamine using octanol as a diluents followed by sodium hydroxide back extraction (Ahsan et al 2013).

Prehydrolysed jute stick was further cooked by soda and kraft processes with EDA addition. As shown in Table 4, both kappa number and pentosan content decreased with the

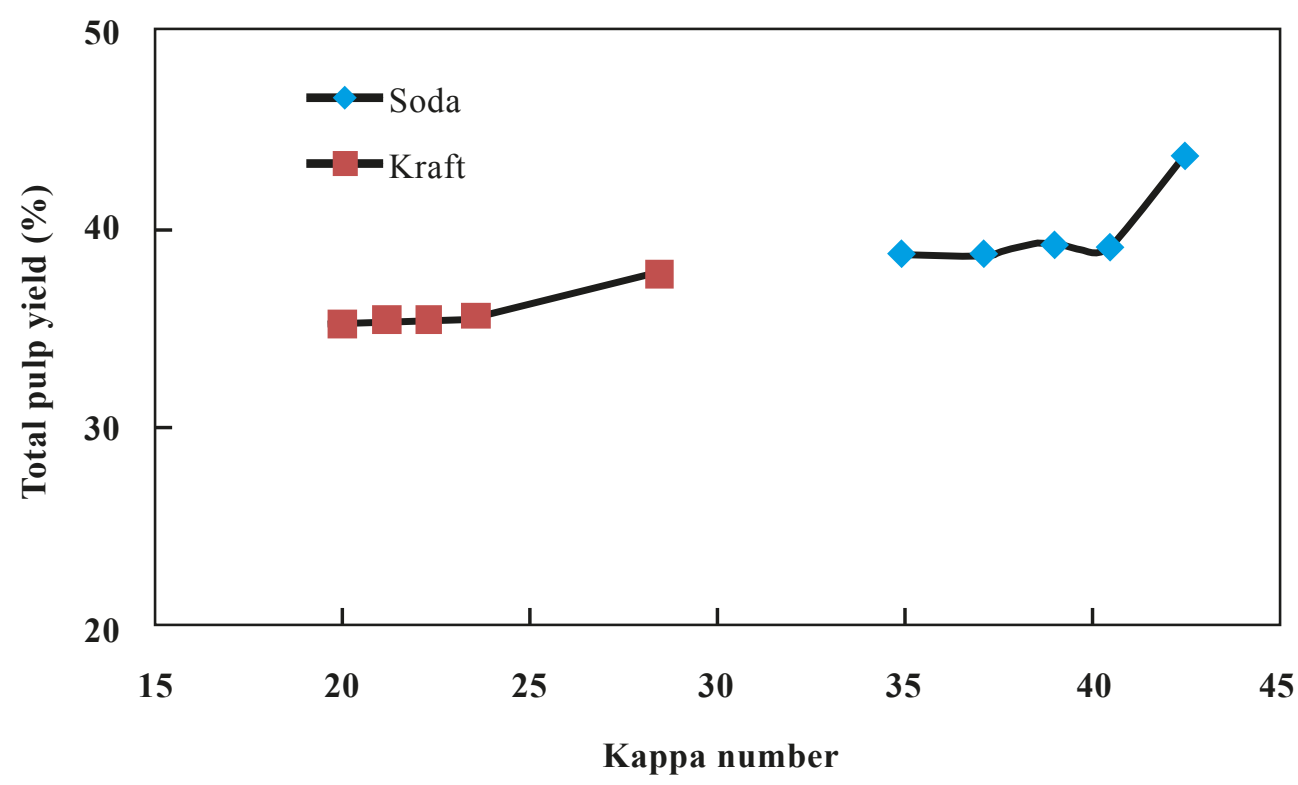

Fig. 1. Pulp yield and kappa number relationship in respect to EDA charge 
addition of EDA in soda or kraft liquor. Kraft process showed promising results in respect to delignification and pentosan dissolution. Addition of 10\% EDA decreased kappa number from 30.8 to 28.3 in soda liquor and from 20.8 to 18.7 in $\mathrm{kraft}$ process; similarly pentosan content also decreased by 1.2 points (Fig. 2). Pulp yield in prehydrolysed soda process was slightly higher than the kraft process, which is due to higher delignification and pentosan dissolution in kraft process. At $10 \%$ EDA addition, pulp yield was $32.2 \%$, which was $0.7 \%$ higher than the kraft process. At this point kappa number and pentosan content were 28.3 and 9.3 for soda process and 18.7 and 8.0 for kraft process, respectively.
$5.4 \%$ (Table 5). Pulps obtained from prehydrolysed and without prehydrolysed soda and kraft processes with $40 \%$ EDA processes were subjected to $D_{0} E_{p} D_{1} E_{p} D_{2}$ bleaching. All pulps were bleached under identical conditions. The purity ( $\alpha$-cellulose) of kraft-EDA pulp reached to $92.8 \%$ without prehydrolysis, which further increased to $94.2 \%$ with the introduction of prehydrolysis step. Soda process did not exhibit expected results even with prehydrolysis step. Degraded cellulose percentage also increased with the introduction of prehydrolysis step as indicated by $\mathrm{R}_{18}-\mathrm{R}_{10}$

Table III. Effect of pre-hydrolysis of jute stick on solid residue and PHL composition

\begin{tabular}{cccccc}
\hline Yield (\%) & \multicolumn{5}{c}{ Pre -hydrolysis liquor } \\
\cline { 2 - 5 } & $\mathrm{pH}$ & Solid content (\%) & Lignin (\%) & Total sugar (\%) & HAc (\%) \\
\hline 89.8 & 4.9 & 8.2 & 0.52 & 5.23 & 0.85 \\
\hline
\end{tabular}

Table IV. Effect of EDA on the pulping of prehydrolysed jute stick

\begin{tabular}{cccc|ccc}
\hline \multicolumn{3}{c|}{ Soda process } & \multicolumn{3}{c}{ Kraft process } \\
\hline EDA & $\begin{array}{c}\text { Pulp yield } \\
(\%)\end{array}$ & $\begin{array}{c}\text { Kappa } \\
\text { Number }\end{array}$ & Pentosan (\%) & $\begin{array}{c}\text { Pulp } \\
\text { yield (\%) }\end{array}$ & $\begin{array}{c}\text { Kappa } \\
\text { Number }\end{array}$ & Pentosan (\%) \\
\hline 0 & 33.4 & 30.8 & 10.5 & 33.0 & 20.8 & 9.2 \\
10 & 32.2 & 28.3 & 9.3 & 31.5 & 18.7 & 8.0 \\
20 & 32.0 & 27.4 & 8.2 & 31.3 & 18.3 & 7.2 \\
30 & 30.4 & 26.3 & 7.8 & 30.9 & 18.0 & 6.4 \\
40 & 30.0 & 24.8 & 7.0 & 29.9 & 17.2 & 5.7 \\
\hline
\end{tabular}

\section{Bleaching}

The amount of residual pentosan (Table 5) reflects the degree of purity, which is crucial for the production of rayon fibers and products made from cellulose acetate. In the case of hardwood, the major hemicellulose component is 4-O-methyl glucuronoxylan, which can be easily identified by xylose. Prehydrolysed-kraft-EDA pulp showed highest purity, where residual xylose content was
(6.4 and 7.6 vs 7.1 and 9.0). Pulp obtained under prehydrolysed jute stick had higher brightness than those of without prehydrolysed brightness. The prehydrolysis step decreased final pulp viscosity in both soda and kraft process. Viscosity of bleached pulp from kraft process was $5.8 \mathrm{mPa}^{*} \mathrm{~s}$ and $3.8 \mathrm{mPa}^{*} \mathrm{~s}$ for prehydrolysis and without prehydrolysis step, respectively. 
Table V. Dissolving pulp properties after bleaching of soda- and kraft-EDA pulp

\begin{tabular}{|c|c|c|c|c|c|c|c|}
\hline & Process & $\begin{array}{c}\text { Pentosan } \\
(\%)\end{array}$ & $\mathrm{R}_{10}(\%)$ & $\mathrm{R}_{18}(\%)$ & $\begin{array}{c}\alpha-\text { cellulose } \\
(\%)\end{array}$ & $\begin{array}{c}\text { Brightness } \\
(\%)\end{array}$ & $\begin{array}{c}\text { Viscosity } \\
\text { mPa.s }\end{array}$ \\
\hline \multirow{2}{*}{$\begin{array}{l}\text { Without } \\
\text { prehydrolysis }\end{array}$} & Soda & 9.7 & 82.0 & 88.4 & 89.1 & 85.1 & 6.8 \\
\hline & Kraft & 8.2 & 82.4 & 90.0 & 92.8 & 89.7 & 5.8 \\
\hline \multirow[t]{2}{*}{ Prehydrolysis } & Soda & 9.0 & 82.1 & 89.2 & 90.3 & 87.2 & 6.3 \\
\hline & Kraft & 5.4 & 84.8 & 93.8 & 94.2 & 90.3 & 3.8 \\
\hline
\end{tabular}

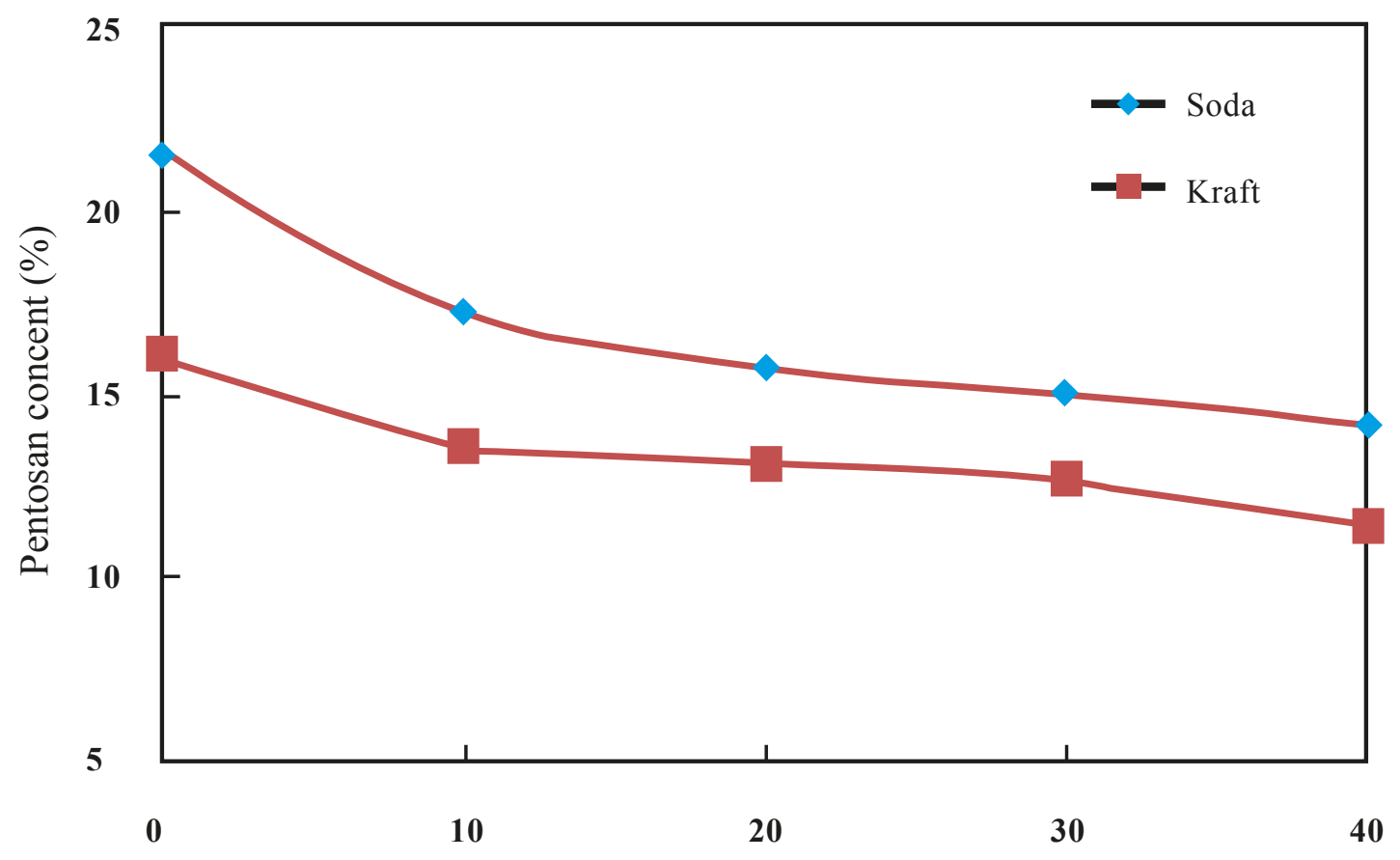

EDA charge (\%)

Fig. 2. Effect of EDA charge on the pentosan dissolution 


\section{Conclusion}

Presence of EDA in soda and kraft liquor improved delignification and pentosan dissolution. Kraft process exhibited better results. The purity $(\alpha$-cellulose $)$ of kraft-EDA pulp reached to $92.8 \%$ without prehydrolysis, which increased to $94.2 \%$ with the introduction of prehydrolysis step. Prehydrolysis step increased degraded cellulose percentage as observed by $R_{18}-R_{10}$ (6.4 and 7.6 vs 7.1 and 9.0). Prehydrolysis step decreased viscosity of the produced pulp. It can be said that EDA in kraft liquor produced dissolving pulp without prehydrolysis step and the produced pulp can be used in rayon production.

\section{Acknowledgement}

Authors wish to thanks BCSIR authority to provide fund to carry out this research from $\mathrm{R}$ and $\mathrm{D}$ project.

\section{References}

Ahsan, L., Jahan, M. S., \& Ni, Y. (2013). Recovery of Acetic Acid from the Prehydrolysis Liquor of Kraft Based Dissolving Pulp Production Process: Sodium Hydroxide Back Extraction from the Trioctylamine/Octanol System. Industrial \& Engineering Chemistry Research, 52(26): 9270-9275.

Biermann CJ, (1993) Essentials of Pulping and Papermaking. Academic Press, New York, 72-100

Bustos, G., De la Torre, N., Moldes, A. B., Cruz, J. M., \& Domínguez, J. M. (2007). Revalorization of hemicellulosic trimming vine shoots hydrolyzates trough continuous production of lactic acid and biosurfactants by L. pentosus. Journal of food engineering, 78(2): 405-412.

Das, M. (1980). Utilisation of Jute Sticks in Paper Industry. Economic and Political Weekly, 1679-1684.

Das, R. N., Day, A., \& Pandey, S. N. (1987). Particle boards from jute stick. Biological wastes, 20(4): 309-313.

Day, A., Chattopadhay, S. N., Ghosh, I. N., \& Bhaduri, S. K. (2007). Cellulose derivatives from jute stick, an agrowaste. IPPTA, 19(3): 145.

Hinck JF, Casebier RL, Hamilton JK, (1985) Pulp and Paper Manufacture (O.V. Ingruder, J. J. Kocurek, and W.Wong, Eds.), vol. 4, TAPPI PRESS, Atlanta, pp. 213-243.
Hughes, J. (2008). U.S. Patent No. 7,455,997. Washington, DC: U.S. Patent and Trademark Office.

IJSG (2014) http://jute.org/statistics_search.php

Jahan MS, Farouqui FI (2000) Pulping of whole jute plant ( $C$. Capsularis) by soda-amine process. Holzforschung. 54(6): 625-630.

Jahan MS (2001) Evaluation of additives in soda pulping of jute. Tappi J. 84(8): 1-11.

Jahan, M. S., Ahsan, L., Noori, A., \& Quaiyyum, M. A. (2008). Process for the production of dissolving pulp from trema orientalis (Nalita) by prehydrolysis kraft and soda-ethylenediamine (EDA) process. BioResources, 3(3), 816-828.

Jahan, M. S. (2009). Studies on the effect of prehydrolysis and amine in cooking liquor on producing dissolving pulp from jute (Corchorus capsularis). Wood science and technology, 43(3-4), 213-224.

Julien LM, Sun BCH, (1979). Pulping with amine and soda-amine systems. Tappi J, 62(8): 63-65.

Krässig, HA (1993) Cellulose - Structure, Accessibility and Reactivity. Polymer Monographs Vol. 11. M. B. Huglin. Amsterdam, Gordon and Breach science publishers.

Kubes GJ, Bolker HI, (1978) Sulphur free delignification I. Alkaline pulping with monoethanolamine and ethylene diamine. Cellulose Chem. Technol, 12(5): 621-645.

Kubes GJ, Fleming BI, MacLeod JM, Bolker HI, (1978) Sulphur free delignification Tappi, 61(8): 46-50.

Liu, H., Hu, H., Jahan, M. S., \& Ni, Y. (2013). Furfural formation from the pre-hydrolysis liquor of a hardwood kraft-based dissolving pulp production process. Bioresource technology, 131: 315-320.

MacLeod JM, Iwase H, Bolker HI, (1984) The carbohydrate composition of soda-additive pulps. Tappi J. 67(5): 123-124.

Matin, M., Rahaman, M. M., Nayeem, J., Sarkar, M., \& Jahan, M. S. (2015). Dissolving pulp from jute stick. Carbohydrate Polymers, 115: 44-48. 
Miao, Q., Chen, L., Huang, L., Tian, C., Zheng, L., \& Ni, Y. (2014). A process for enhancing the accessibility and reactivity of hardwood kraft-based dissolving pulp for viscose rayon production by cellulase treatment. Bioresource technology, 154: 109-113.

Pandey S.N., GhoshI.N., DeyA., (1995). Utilization of nonwood fibrous raw material for pulp, paper and board. Research and Industry, 40: 285-288

Sjöström E (1981) Wood Chemistry: Fundamentals and Applications. Academic Press, New York, 169-189.
Tian, C., Zheng, L., Miao, Q., Cao, C., \& Ni, Y. (2014). Improving the reactivity of kraft-based dissolving pulp for viscose rayon production by mechanical treatments. Cellulose, 21(5): 3647-3654.

Received: 16 February 2015; Revised: 02 March 2015 Accepted: 24 March 2015. 